\title{
Laboreal
}

Volume $10 \mathrm{~N}^{\circ} 1$ | 2014

Análise ergonómica do trabalho e formação

\section{Análise da atividade, participação e sustentabilidade da ação transformadora: reflexões a partir do Projeto Matriosca}

Análisis de la actividad, participación y sustentabilidad de la acción transformadora: reflexiones a partir del Proyecto Matriosca

Analyse de l'activité, participation et durabilité de l'action transformatrice: réflexions à partir du Projet Matriosca

Activity analysis, participation and sustainability of the transformative action: reflections from the Matriosca Project

\section{Sérgio Duarte e Ricardo Vasconcelos}

\section{OpenEdition}

\section{Journals}

\section{Edição electrónica}

URL: http://journals.openedition.org/laboreal/5205

DOI: 10.4000/laboreal.5205

ISSN: 1646-5237

\section{Editora}

Universidade do Porto

\section{Refêrencia eletrónica}

Sérgio Duarte e Ricardo Vasconcelos, « Análise da atividade, participação e sustentabilidade da ação transformadora: reflexões a partir do Projeto Matriosca », Laboreal [Online], Volume 10 NN$^{0} 1 \mid 2014$, posto online no dia 01 julho 2014, consultado o 12 outubro 2019. URL : http:// journals.openedition.org/laboreal/5205; DOI : 10.4000/laboreal.5205

Este documento foi criado de forma automática no dia 12 outubro 2019.

\section{(c) (i) \$}




\section{Análise da atividade, participação e sustentabilidade da ação transformadora: reflexões a partir do Projeto Matriosca}

Análisis de la actividad, participación y sustentabilidad de la acción transformadora: reflexiones a partir del Proyecto Matriosca

Analyse de l'activité, participation et durabilité de l'action transformatrice:

réflexions à partir du Projet Matriosca

Activity analysis, participation and sustainability of the transformative action: reflections from the Matriosca Project

Sérgio Duarte e Ricardo Vasconcelos

\section{NOTA DO EDITOR}

http://dx.doi.org/10.15667/laborealx0114sd

Manuscrito recebido em: setembro/2013

Aceite após peritagem: novembro/2013

Este trabalho foi apoiado pela Universidade do Porto e por uma Bolsa da FCT (SFRH / BD / 70753 /2010)

\section{Introdução: a participação como meio para uma intervenção sustentável e sustentada no real}

1 A ideia da participação, como conceito guarda-chuva que abrange todas as intervenções em que é solicitado o envolvimento de trabalhadores e que inclui denominações tão 
diferentes como empowerment, voz ou envolvimento (Wilkinson \& Dundon, 2010), tem, por isso talvez, encontrado forte aceitação e legitimidade social (Gonzalez, 2009). A sua génese humanista tem contribuído para este largo consenso, funcionando como um contraponto a um tipo de gestão autoritária (Likert, 1961) e considerando como elementos estruturantes do ser humano a necessidade de controlo sobre os seus próprios comportamentos e consequências (Argyris, 1957) e a procura constante de um significado em todas as suas ações (McGregor, 1960). Mas, o processo participativo também é valorizado pelo seu lado funcional (Lamonde, 1995), relacionando-o com a importância do conhecimento e da experiência dos trabalhadores construída no confronto diário com o trabalho real e com o potencial de rentabilizar esse conhecimento, seja para melhorar as condições de trabalho, a segurança, a produtividade ou a qualidade.

2 Esta conceção funcional de participação tem sido cada vez mais validada, até ao ponto em que hoje em dia há claramente uma maior disseminação de práticas participativas. Assim, análises como a de Gonzalez (2009) apontam para evidências de uma relação entre vários tipos de participação direta e variáveis como produtividade, perceção de influência, clima organizacional ou confiança, maiores salários, segurança no emprego e perspetivas de promoção.

$3 \mathrm{Na}$ área da "Ergonomia Participativa", que procura explicitamente envolver os trabalhadores no planeamento e controlo das suas atividades de trabalho (Wilson \& Haines, 1997) e que tem preocupações que convergem com as que orientaram o estudo de caso que estamos a apresentar, algumas revisões sistemáticas (eg., Cole et al., 2005, Cole et al., 2009, Rivilis et al., 2008, e St. Vincent et al., 2010) evidenciam o impacto globalmente positivo da participação, considerando outros indicadores como a diminuição de lesões músculo-esqueléticas, a melhoria da qualidade das alterações efetuadas, a redução de dias perdidos por baixa e das indemnizações pagas.

4 Vários autores que se situam nesta tradição, realçam também o aperfeiçoamento de soluções devido à experiência desenvolvida durante o trabalho (Imada, 1991; StVincent, Fernandez, Kuorinka, Chicoine, \& Beaugrand, 1997), insistindo na possibilidade de o processo de participação representar uma experiência de aprendizagem para todos os envolvidos (St. Vincent et al. 1997; Wilson et al., 2005). Maciel (1998) conclui com a possibilidade de estes processos levarem a melhorias não só nos processos de trabalho mas também no bem-estar dos trabalhadores.

5 No entanto, mesmo na vertente funcional da participação, este aparente "consenso" deve ser olhado com algumas reservas, principalmente se tivermos em conta a grande diversidade de cenários propostos sob a designação de projetos participativos. 0 Participatory Ergonomics Framework, grelha desenvolvida por Haines, Wilson, Vink e Koningsveld (2002), oferece-nos um bom exemplo da diversidade de abordagens que podem ser enquadradas na área da "Ergonomia Participativa".

$6 \mathrm{Na}$ verdade, se a valorização do conhecimento adquirido pelos trabalhadores no decurso da atividade é fundamental, ele parece também servir de fundamento para definir intervenções com metodologias e regras diferentes.

7 É de admitir por isso que, mesmo no que diz respeito à sua conceção funcional, o recurso ao conceito de "participação" mantém a sua ambiguidade, nomeadamente porque não deixa de revelar uma relação desigual, entre quem decide abrir um espaço e um tempo para permitir a participação - e os "outros". De acrescentar que esta 
ambiguidade é ainda mais complexa se tivermos em conta que, frequentemente, numa organização, são várias as instâncias e os atores que exercem o poder de decisão: a gestão desta transferência de poder entre diferentes estruturas hierárquicas e os limites explícitos e implícitos que a orientam contribuem para a complexidade deste tipo de intervenções.

8 Na realidade, a maior parte das intervenções de participação direta implicam esta abordagem de "cima para baixo" (Wilkinson \& Dundon, 2010). Os responsáveis pela gestão decidem conceder algum poder aos trabalhadores com objetivos normalmente predeterminados e com limites bem definidos. Esta escolha envolve necessariamente tensões entre interesses contraditórios e incorpora camadas de complexidade que muitas vezes operam finalmente contra os objetivos da participação.

Esta complexidade inerente às intervenções participativas faz com que, por vezes, estas constituam um "negócio arriscado" (Garrigou, 2002). De facto, as intervenções podem falhar e levar à desilusão das pessoas envolvidas, que se sentem enganadas por a sua contribuição não ter levado nem à prossecução dos resultados anunciados, nem à melhoria das condições de trabalho (Garrigou, 2002). As intervenções participativas podem até ser utilizadas, tal como Wells (1987) defendeu, como uma maneira de manipular os trabalhadores, levando-os a acreditar que estão a ser envolvidos, quando afinal estão a ser marginalizados das decisões que realmente têm impacto ao nível do seu trabalho e dos verdadeiros problemas que os afetam - motivo que levou a que vários sindicatos tenham uma atitude ambivalente face aos processos de participação direta. Apontam ainda que, ao dar aos trabalhadores uma influência que, na verdade, será pouco real ou revestirá uma forma híbrida de delegação de poder (Potterfield, 1999), poderá, sobretudo, reforçar a "tentação responsabilizadora", apostando na motivação e na capacidade dos trabalhadores para resolverem as dificuldades com que se confrontam, sem intervir sobre a sua fonte (Lacomblez \& Vasconcelos, 2009).

10 Assim, nem sempre os resultados da participação acabam por beneficiar aqueles que alimentaram o processo (Garrigou, 2002). Até os ganhos associados ao aumento de produtividade ocasionados por práticas participativas nem sempre são transferidos para os trabalhadores (Gonzalez, 2009), podendo até resultar em despedimentos...

11 A cautela no uso do termo participação é então justificada. Se considerarmos que não pode deixar de constituir uma dimensão estruturante de qualquer intervenção sustentada no real, é necessário criar condições que irão garantir que o recurso à participação servirá de facto aqueles que estarão envolvidos no processo, originando mudanças profundas e duradouras na organização. Mais do que solicitar pontualmente o contributo dos trabalhadores, a preocupação é que este se torne permanente.

12 É com esta olhar, que iremos analisar a dimensão participativa da intervenção que se descreve a seguir, procurando avaliar não só se o recurso ao contributo dos trabalhadores contribuiu para uma melhoria das suas condições de trabalho, mas também se as mudanças que originaram acabaram por ter um impacto de longo prazo.

13 Nesse sentido, temos considerado a análise da atividade de trabalho (e o envolvimento de profissionais que dominem esta competência no processo) como pilar fundamental da nossa abordagem.

14 Por um lado, porque a assumpção do trabalho em toda a sua complexidade, a valorização da experiência construída pelos trabalhadores e a aposta no conhecimento gerado pela troca e confrontação de saberes (Lacomblez \& Teiger, 2007), próprios a esta 
análise, tornam o processo participativo imprescindível $\mathrm{e}$ realça as suas potencialidades: a análise da atividade é vista como "ferramenta cognitiva", conduzindo a um outro olhar sobre o trabalho, realçando aspetos antes pouco ou mal conhecidos, e encaminhando para novos cenários de transformações (Teiger \& Lacomblez, 2013). Trata-se de um processo enriquecedor quer na dimensão da formação quer na dimensão da transformação, com impacto efetivo e consequente nas condições de trabalho.

15 Mas por outro lado, consideramos a análise da atividade como forma de garantir que uma intervenção participativa seja justa e tenha um impacto positivo no trabalho de quem nela contribui: por abranger necessariamente a gestão de processos de tomada de decisões, a dinâmica sustentada é de transferência, pelo menos parcial, de poderes e convoca então a questão da justiça.

\section{O Projeto Matriosca}

\subsection{0 método}

\subsubsection{0 contexto da intervenção}

16 A empresa em que ocorreu a intervenção situa-se num Complexo Químico em Portugal, com dois polos de produção, e emprega cerca de 220 trabalhadores. O primeiro polo produz compostos inorgânicos e é constituído por quatro fábricas cujos processos de produção são interdependentes. O segundo polo é responsável pela produção de compostos orgânicos através de processos de síntese em reatores e é constituído por cinco fábricas. Os dois polos são interdependentes, comunicando através de condutas de vapor e hidrogénio.

Cinco turnos asseguram o funcionamento da empresa 24 horas por dia. Por cada fábrica da empresa, existem dois operadores por turno: um operador de painel, responsável pelo controlo da automação do processo produtivo através de vários monitores onde pode controlar indicadores como temperaturas, pressões e concentrações; e um operador responsável pela fábrica no seu exterior onde executa várias operações de controlo de qualidade do produto, estando sempre em estreita articulação com o operador de painel da fábrica.

\subsubsection{Os motivos para a intervenção}

18 A intervenção foi desenvolvida na empresa em resposta a um pedido que visava o desenho de um projeto com vista à promoção da segurança industrial e ambiental (Duarte, Vasconcelos \& Pinto, 2011). Desde os primeiros contactos com os responsáveis pela empresa, foi possível verificar que as principais preocupações em matéria de Segurança e Saúde no Trabalho tinham a ver com acidentes industriais com substâncias químicas perigosas (tóxicas, corrosivas ou inflamáveis) como fugas, derrames ou libertações para a atmosfera. Estes acidentes industriais acarretam fortes consequências para a empresa e para a comunidade que pode ser atingida, já que um acidente na empresa ultrapassa os muros desta podendo afetar a população envolvente. Assim, mais do que o imperativo legal associado às coimas das autoridades ambientais, a segurança na empresa tem um forte imperativo social e comunitário. Para além disto, 
a segurança é ainda uma necessidade económico-financeira do mercado enquanto critério de negociação de parcerias entre empresas.

\subsubsection{Os participantes}

Acompanhamento", estrutura mobilizada pela intervenção cuja função será descrita mais à frente. Neste comité fazem-se representar as várias direções da empresa: Direção de Produção; Direção Técnica; Direção de Manutenção; Direção da Segurança, Higiene e Ambiente; e Direção de Recursos Humanos. A estes elementos juntam-se um representante de cada um dos 10 grupos e os três psicólogos do trabalho que assumem a coordenação da intervenção.

\subsubsection{A abordagem metodológica} do Trabalho e de Riscos Ocupacionais para Supervisores, Chefias e estruturas de Apoio) (Vasconcelos, 2008) tem como referencial privilegiado o método de formação-ação definido por Teiger e Laville (1991). Contudo, enquanto o projeto de Teiger e Laville (1991) tinha como objetivo ajudar representantes sindicais a estruturarem melhor as suas reivindicações, o projeto Matriosca foi concebido na sequência da experiência realizada graças ao método MAGICA (Vasconcelos, 2000; Vasconcelos \& Lacomblez, 2000), definido considerando a dinâmica de uma empresa do setor privado, caracterizada por outro tipo de relações sociais em que dominam desigualdades em termos de relações laborais e hierárquicas. 0 objetivo passará então por, através da participação, conferir um maior equilíbrio a essas relações gerindo da melhor forma possível as complexidades inerentes a um processo deste género.

No plano formativo, o Projeto Matriosca procura articular dois tipos de momentos: de análise guiada da atividade de operadores em posto de trabalho; e de análise coletiva em sala de formação em que os resultados da análise em posto são partilhados e discutidos. Como já foi referido, nos 10 grupos constituídos no caso aqui em análise, para além dos operadores industriais, estavam representados outros atores considerados pertinentes para as atividades e problemas em discussão. Quanto ao trabalho de coordenação do processo, este foi executado pela equipa de Psicólogos do Trabalho, três neste caso, todos eles conhecedores das metodologias de análise da atividade (doravante, esta equipa passará a ser designada de "psicólogos do trabalho").

Por já o termos relatado com maior pormenor em diferentes contextos (Vasconcelos, 2008; Lacomblez \& Vasconcelos, 2009; Vasconcelos, Duarte \& Moreira, 2010; Duarte, Pinto \& Vasconcelos, 2011; Vasconcelos, Silva \& Fortuna, 2011), descreveremos aqui de forma sucinta os momentos e as opções metodológicas do projeto, centrando-nos depois na avaliação da intervenção.

Na figura 1 é apresentada esquematicamente a lógica do que podemos designar de "formação-ação participativa", tal como desenvolvida ao longo da intervenção. A base é

Laboreal, Volume $10 \mathrm{~N}^{\circ} 1$ | 2014 
a de um movimento cíclico em que formação e transformação das condições de trabalho se alimentam mutuamente num processo intercomunicante. $O$ processo aqui descrito decorreu entre março de 2010 (início do processo de análise de atividade) e junho de 2012. 0 cronograma pode ser observado com maior detalhe na Figura 2.

Figura 1: A lógica de formação-ação participativa do Matriosca

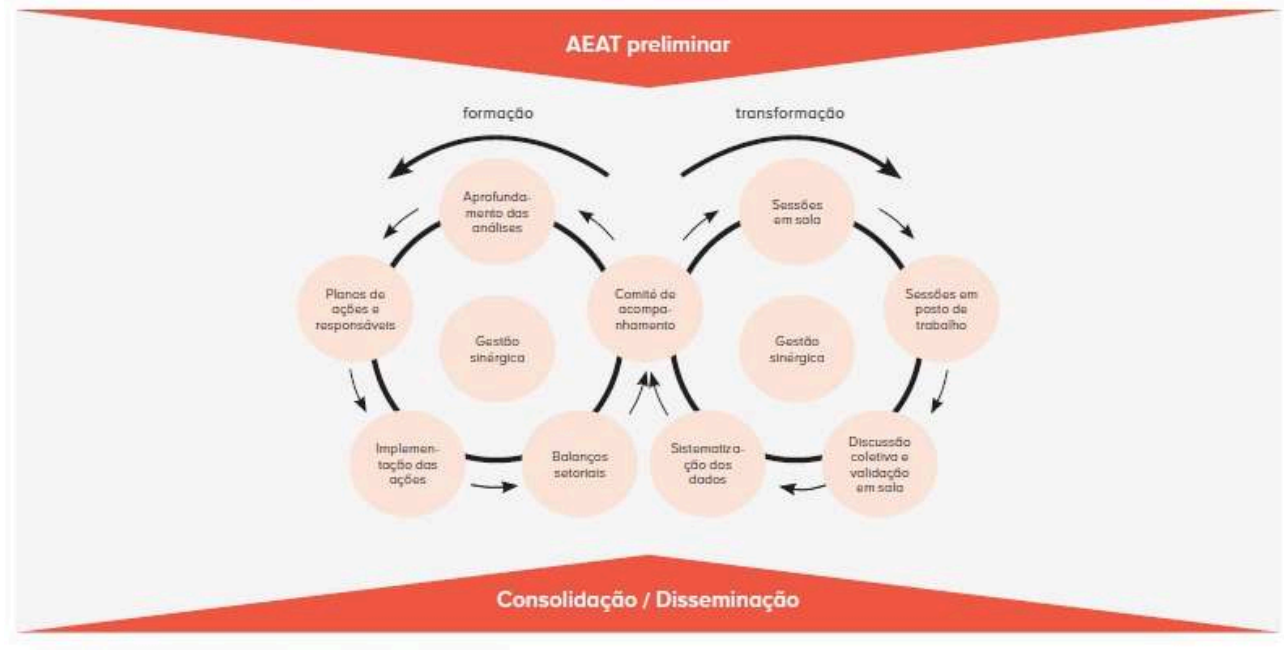

Figura 1: A lógica de formaçao-açao participativa do Matriosco

Primeira fase: Conhecer o terreno e o trabalho real

Os primeiros passos da intervenção consistiram numa recolha de dados considerados necessários para o conhecimento da realidade de trabalho e para a definição das situações que mais tarde serão alvo da intervenção. Consistiu principalmente na consulta de documentos internos e na realização de entrevistas a vários atores por parte dos psicólogos do trabalho. Num segundo momento, e durante cerca de um mês, os mesmos procederam à análise ergonómica das atividades de trabalho que se revelavam pertinentes para o entendimento das situações em causa. Nesta fase, a análise da atividade incidiu, não só na atividade dos operadores industriais, mas também nas atividades dos técnicos de manutenção, técnicos de segurança, supervisores e coordenadores de produção. É a partir dos relatos durante a análise dessas atividades que surgiram situações-problema quotidianas (com implicações ao nível da saúde e segurança, qualidade ou organização temporal) relevantes. Estas foram recolhidas e registadas pelos psicólogos do trabalho com o intuito de servirem de estímulo para a discussão nos grupos de formação.

Convém referir aqui que "situação-problema" foi o termo designado para classificar aspetos críticos do trabalho - considerando, para a sua compreensão, as ações e compromissos necessários para a sua resolução, analisando deste modo os "desvios" entre o prescrito e o real reveladores do aspeto "problemático" das situações. Estas "disfunções" no desenrolar supostamente normal do sistema de produção, muitas vezes de caráter imprevisto, são aquilo que Zarifian (1999) designa de "eventos". É, precisamente, a apreensão, partilha e discussão destes eventos que permite um novo olhar sobre a atividade e a elaboração de um projeto de intervenção orientado pela vontade de uma melhoria das condições de trabalho.

Esta fase decorreu entre os meses de março e abril de 2010 (cf. Figura 2).

Segunda fase: Grupo de formação e análise em alternância 
30 Após o momento de análise inicial, é colocado em marcha o movimento cíclico do polo da formação com as sessões em sala. Como é possível observar na figura 1, a vertente da formação, ilustrada no polo da direita, é composta por 4 fases: sessão em sala com o grupo; sessões em posto de trabalho; balanço em sala; e sistematização dos dados. Assim, com cada um dos sucessivos 10 grupos, o trabalho de análise passou, em duas semanas, por alternar momentos de análise coletiva em sala de formação e momentos de análise guiada em posto de trabalho com cada elemento que constitui o grupo em causa.

31 Depois de realizado o trabalho com cada um dos grupos, as conclusões são comunicadas ao "Comité de Acompanhamento", estrutura mobilizada pela intervenção, funcionando como eixo central, pois assegura as condições indispensáveis para a concretização das ações desenhadas (Vasconcelos, Silva \& Fortuna, 2011).

A presença no Comité de Acompanhamento de diversos atores pertencentes a diferentes estruturas hierárquicas, e com um maior poder na tomada de decisões, facilita a implementação das ações propostas e a materialização do que permitiu o processo participativo, assegurando que os participantes são implicados não só no diagnóstico e na investigação de soluções mas, também, na implantação, levando a um processo de transformação.

33 Este processo e a discussão promovida neste Comité realimenta o processo de formação em curso, seja materialmente, pela introdução de novos elementos nas análises e discussões subsequentes, seja emocionalmente, pela constatação dos sujeitos em formação do impacto real e quase imediato que a sua ação vai tendo.

34 Assim, com o Comité de Acompanhamento numa posição de charneira do processo participativo, é sustentado o outro polo, o da transformação das condições de realização do trabalho (polo da esquerda, figura 1) cujo ciclo está, também ele, dividido em quatro partes: o aprofundamento das análises realizadas em contexto de grupo, a elaboração de planos de ações e atribuição desses planos a responsáveis internos para a resolução de problemas levantados nos grupos, a implementação dessas ações e balanços setoriais de acompanhamento (reuniões com os responsáveis internos e encontros com elementos das diversas áreas da empresa para analisar o ponto de situação da implementação das ações).

Cada ciclo de formação-transformação tem a duração aproximada de um mês, correspondendo uma semana à preparação específica do trabalho em sala, duas semanas à análise em alternância e uma semana para a preparação e concretização da reunião com o Comité de Acompanhamento. 0 trabalho do primeiro grupo ocorreu no mês de maio de 2010 e o do décimo e último grupo no mês de junho de 2011.

Para além da moderação destes momentos formais (momentos de análise guiada em posto de trabalho, análise coletiva em sala de formação e reuniões do Comité de Acompanhamento), os psicólogos do trabalho desenvolvem um conjunto de atividades essenciais para uma boa prossecução do processo ao nível logístico (preparação de materiais, atualização de bases de dados de situações-problema, atualização dos diários de investigação) e, a outros níveis, com consultas informais com outros stakeholders envolvidos nas atividades em causa e importantes para a tomada de decisões, balanços setoriais ou reuniões de preparação. Estas últimas atividades enquadram-se na categoria "Gestão sinérgica do processo" que está representada na Figura 1 no centro dos ciclos de formação e de transformação, simbolizando assim o papel importante que 
este trabalho, nem sempre visível, tem para o desenvolvimento da intervenção e da gestão dos compromissos necessários para a pôr em prática. empresa, os psicólogos do trabalho elaboraram um procedimento para a implementação de uma nova fase do processo que visava atribuir aos elementos da Direção de Segurança, Higiene e Ambiente a liderança da prossecução dos objetivos do Matriosca, de uma forma autónoma, sem a presença e mediação especialista dos psicólogos.

O procedimento para esta intervenção, designado como "Matriosca Interno", foi apresentado à empresa em abril de 2012. Entre a sua apresentação e a primeira sessão que ocorreu em junho de 2012 (cf. Figura 2), que foi acompanhada por um dos psicólogos do trabalho, foram criadas as condições logísticas próprias ao Matriosca Interno (organização de equipas, preparação do material, etc.). Esse mesmo psicólogo do trabalho regressou recentemente à empresa (cf. Figura 2 - última linha do Cronograma) para efetuar um follow up da experiência, estando neste momento a ser negociados com a empresa os moldes de uma avaliação detalhada. 
Figura 2: Cronograma do Projeto Matriosca

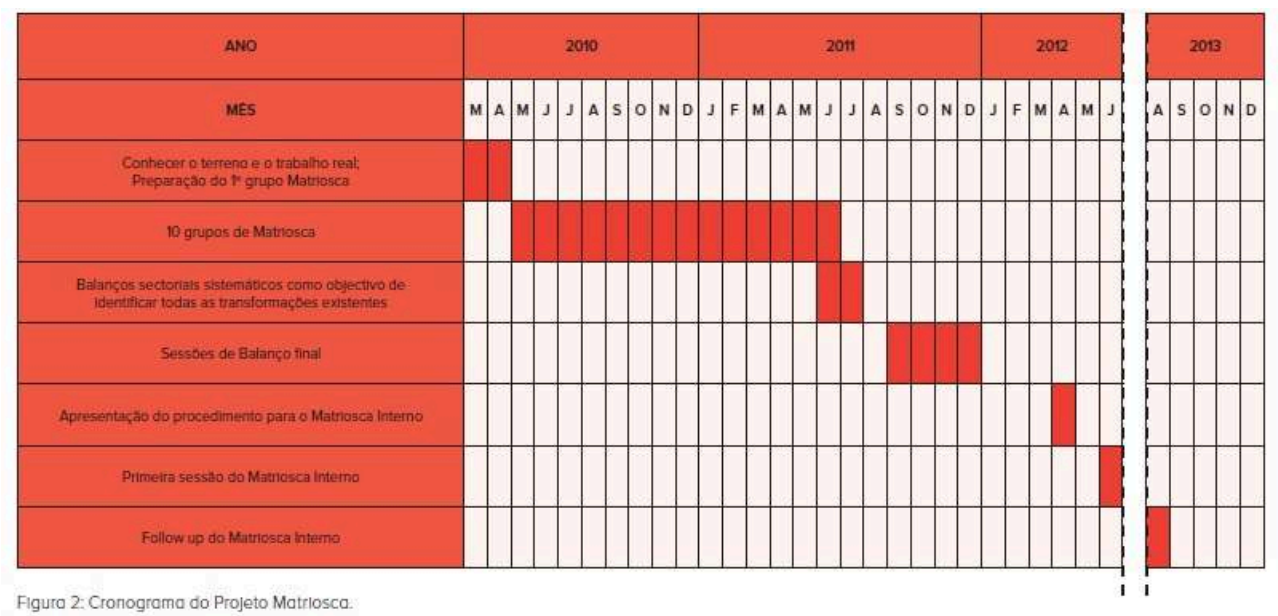

\subsection{Os primeiros resultados}

A caracterização do impacto deste processo de intervenção, imediato e a longo prazo, terá necessariamente que focar diversas dimensões. Todas elas são interligadas; mas a sua análise "segmentada" permitirá compreender o processo de transformação originado inicialmente e sua sustentabilidade. Três dimensões passarão então a ser objeto de atenção: (i) o processo de transformação; (ii) a perceção da participação e (iii) a transição para o Matriosca Interno e a permanência do processo. Pretender-se-á: na primeira dimensão, referir o impacto imediato da metodologia nas condições do trabalho; na segunda dar conta da perspetiva dos participantes sobre esse mesmo processo; e na terceira descrever a tentativa de garantir a sustentabilidade do processo a longo prazo sem a intervenção dos psicólogos do trabalho.

\subsubsection{O processo de transformação}

Categorias e estados das situações-problema identificadas

Na Tabela 1 pode ser observado o estado e as diferentes categorias das 194 situaçõesproblema identificadas ao longo da intervenção.

A categoria "condições de trabalho" diz respeito a situações diretamente relacionadas com as condições materiais de execução do trabalho; a categoria "organização do trabalho" é referente a situações relativas à organização interna do processo de trabalho que não envolvam a necessidade de modificação de condições; a categoria "comportamentos e atitudes" engloba situações mais diretamente relacionadas com questões comportamentais; a categoria "melhorias ao processo" abrange sugestões de melhoria, mesmo que não diretamente relacionadas com a segurança no trabalho; e a categoria "organização formal/informal" diz respeito a situações ilustrativas das diferenças entre os procedimentos prescritos e as condições reais de execução do trabalho [1].

A definição destas categorias foi feita após o início do processo e advém de uma necessidade de adaptação a conceitos pré-existentes no terreno e de discriminação entre as situações-problema, uma questão essencial para a comunicação entre atores e para o processo de transformação em si. É a instrumentalidade das categorias que deve 
ser considerada pois é esta que lhes confere sentido - mesmo que a sua designação possa parecer contraditória com os princípios epistemológicos da intervenção.

Depois da última reunião do Comité de Acompanhamento do Projeto Matriosca, tinham sido intervencionadas 87 situações, na sua maioria relativas a "condições de trabalho" (44 foram resolvidas, 27 estavam em processo de resolução e 16 foram objeto de intervenção mas não tinham sido resolvidas), pela ação direta dos grupos de formação em estreita relação com as suas chefias e diferentes engenharias de apoio à produção.

O facto de a maioria das situações-problema estar incluída na categoria "condições de trabalho" (140 em 194) reflete o ponto de partida do Projeto, pautado desde o seu início pela finalidade de uma transformação das condições de trabalho. $O$ aparecimento de outras categorias surgiu, como já foi referido anteriormente, com o desenrolar do processo.

Tabela 1: Ponto de situação das situações-problema por categoria

\begin{tabular}{|c|c|c|c|c|c|c|}
\hline \multirow{2}{*}{$\begin{array}{lr}\text { Estado } & \text { de } \\
\text { evolução } & \text { das } \\
\text { situações- } & \\
\text { problema } & \end{array}$} & \multicolumn{6}{|c|}{ Categorias das situações-problema } \\
\hline & $\begin{array}{l}\text { Condições } \\
\text { de } \\
\text { trabalho }\end{array}$ & $\begin{array}{l}\text { Organização } \\
\text { do trabalho }\end{array}$ & $\begin{array}{l}\text { Comportamentos } \\
\text { e atitudes }\end{array}$ & $\begin{array}{l}\text { Melhorias } \\
\text { ao } \\
\text { processo }\end{array}$ & $\begin{array}{l}\text { Organização } \\
\text { formal/ } \\
\text { informal }\end{array}$ & Total \\
\hline Resolvidos & 40 & 1 & 2 & 1 & 0 & 44 \\
\hline Em resolução & 22 & 3 & 0 & 1 & 1 & 27 \\
\hline \begin{tabular}{l}
\multicolumn{2}{l}{ Intervencionados } \\
mas não \\
resolvidos
\end{tabular} & 10 & 3 & 1 & 0 & 2 & 16 \\
\hline A aprofundar & 5 & 1 & 2 & 3 & 1 & 12 \\
\hline $\begin{array}{l}\text { Parados com } \\
\text { solução } \\
\text { identificada }\end{array}$ & 11 & 0 & 0 & 0 & 0 & 11 \\
\hline $\begin{array}{l}\text { Parados sem } \\
\text { solução } \\
\text { identificada }\end{array}$ & 17 & 4 & 1 & 1 & 3 & 26 \\
\hline Abandonados & 32 & 8 & 3 & 9 & 0 & 52 \\
\hline Sem evolução & 3 & 0 & 1 & 1 & 1 & 6 \\
\hline Total & 140 & 20 & 10 & 16 & 8 & 194 \\
\hline
\end{tabular}

51 De notar que, após a apresentação das situações-problema no Comité de Acompanhamento pelos psicólogos do trabalho conjuntamente com os representantes dos grupos, 52 situações foram "abandonadas" - seja por envolverem riscos considerados irrelevantes para o operador/ambiente (situações que, sendo incomodativas, não constituíam um risco quer para a segurança dos operadores quer 
para o ambiente, como por exemplo, falta de cobertura para a chuva em determinadas zonas), seja pelo facto de a relação custo/benefício da intervenção não a justificar.

Na Tabela 2 podem ser observados os diferentes motivos pelos quais os problemas foram considerados "abandonados".

Tabela 2 - Motivos das situações-problema abandonadas

Situações-problema "abandonadas"

\begin{tabular}{|c|c|c|c|c|c|}
\hline \multirow{2}{*}{ Motivo } & $\begin{array}{l}\text { Substituição do } \\
\text { equipamento }\end{array}$ & $\begin{array}{l}\text { Risco } \\
\text { irrelevante }\end{array}$ & $\begin{array}{l}\text { Custo/ } \\
\text { Benefício }\end{array}$ & $\begin{array}{l}\text { Análise } \\
\text { imprecisa }\end{array}$ & $\begin{array}{l}\text { Analisar noutro } \\
\text { contexto }\end{array}$ \\
\hline & 3 & 25 & 10 & 7 & 7 \\
\hline
\end{tabular}

Evolução das situações-problema identificadas

Para as várias situações-problema que foram objecto de intervenção, foi definido um responsável pela sua implementação e um departamento da empresa para o seu acompanhamento. No gráfico 1 pode ser observado a evolução do número total de situações identificadas e o número de situações já intervencionadas, tendo como referência temporal as reuniões do Comité de Acompanhamento.

\section{Gráfico - Evolução global do número de situações-problema}

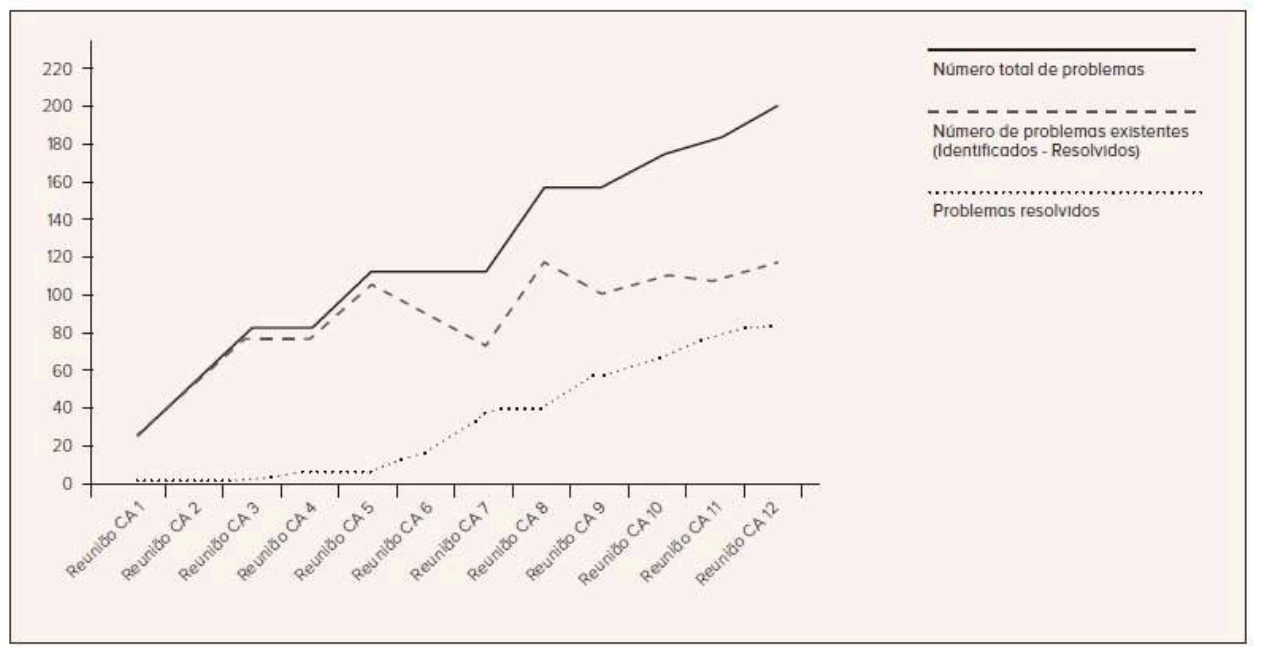

Gróflco t: Evoluçao global do número de situaçoes-problema

Com a recorrente análise das atividades de trabalho pelos psicólogos do trabalho e com o desenvolvimento do trabalho dos grupos, o número absoluto de problemas a apresentar no Comité de Acompanhamento foi aumentando ao longo dos meses. 0 movimento do polo da transformação do trabalho, fortemente impulsionado pelo poder de decisão deste Comité, adquire o seu ritmo a partir da terceira reunião onde já se podem observar duas situações intervencionadas.

Uma análise efetuada à implementação das ações delineadas no Comité de Acompanhamento permite verificar que existe uma relação clara entre estas e as reuniões. 


\section{O duplo movimento de formação e transformação}

Como forma de ilustrar o tipo de trabalho levado a cabo no âmbito do Projeto Matriosca e sua interação com o processo de transformação efetiva, torna-se relevante descrever de uma forma mais detalhada uma das 194 situações-problema identificadas (Caixa de texto 1). 0 exemplo foi escolhido pela sua representatividade no que diz respeito à sobreposição do processo formativo e da atividade dos trabalhadores.

\section{Caixa de texto 1 - Sobrecarga de alarmes}

Os operadores de painel asseguram o controlo remoto das instalações através de um sistema de controlo distribuído ("Distributed Control System") que processa digitalmente, nos monitores do computador, todas as áreas das instalações que estes devem supervisionar (cada operador pode controlar até 5 monitores). Este sistema emite um conjunto de "alarmes" [2] que permitem aos operadores controlarem, antecipadamente, vários indicadores do processo evitando problemas de segurança, de produção ou de qualidade.

1 Quando é necessário realizar um "arranque" [3] das fábricas, o sistema de controlo perde uma parte das suas funcionalidades até ao momento em que o processo produtivo fica estabilizado. Neste período de arranque, o operador de painel controla manualmente o processo, dando resposta aos alarmes que o sistema vai emitindo durante esta fase. Ora, durante o período de arranque os valores dos vários indicadores do processo são inevitavelmente diferentes do que em produção estabilizada, o que leva a que o sistema emita uma série de alarmes a reportar diferenças em relação ao padrão de produção. Com isto, os operadores de painel veem as suas atividades de arranque interrompidas face às centenas de alarmes gerados durante estes períodos (cerca de 450 em situações de arranque), muitos dos quais redundantes ou, até, inúteis. No entanto, se por um lado, estes alarmes nem sempre dão informação relevante para o processo e são simplesmente ignorados e encarados como elementos distratores, por outro lado podem dificultar a identificação de um alarme que seja importante, pondo em risco a segurança das fábricas.

62 A questão dos alarmes revestia-se à data de uma outra problemática. Por questões de segurança, existiam alguns alarmes que surgiam simultaneamente em mais do que um painel de controlo. Apesar de o objetivo desta medida ser o princípio da utilização dos operadores como salvaguarda para o caso de um dos seus colegas não reagir ao alarme, este aspeto acarretava fortes preocupações para o operador, pois para continuar a trabalhar teria que aceitar um alarme "exterior" (de outra fábrica que não a sua), mesmo desconhecendo os fatores que o originaram.

3 Durante o período de análise da atividade e preparação dos grupos de formação levado a cabo pelos psicólogos do trabalho, esta situação relativa à quantidade de alarmes gerados em situações de arranque das fábricas foi identificada pelos operadores como o principal constrangimento das suas atividades, mesmo não sendo reconhecido como problema por mais nenhum ator da empresa. De certo modo configura um exemplo daquilo que é classificado por Wynne (1988) como "anormalidade normal", já que se trata de uma situação anormal e inadequada que foi banalizada e incorporada ao longo do tempo no funcionamento normal da empresa.

Esta situação-problema foi objeto de discussão e validação coletiva em sala no decorrer da realização dos grupos de formação. Posteriormente, no decorrer das reuniões do Comité de Acompanhamento, foi analisada junto das várias chefias e estruturas de 
decisão da empresa. Neste contexto, e após reconhecidos os constrangimentos para os operadores de painel e as implicações de segurança envolvidas, foi definida a criação de uma equipa pluridisciplinar tendo em vista a reconfiguração dos alarmes no painel de controlo. Este trabalho implicou a análise detalhada de cada um dos alarmes daquela fábrica a fim de eliminar eventuais redundâncias. Registou-se uma diminuição na ordem dos $50 \%$ do número de alarmes gerados tanto em situações de arranque, como em situações de funcionamento estável das instalações. Para além da redução significativa do número de alarmes gerados, foi ainda possível definir que, ao contrário do que acontecia anteriormente, os alarmes mais importantes passariam a aparecer no início das páginas de alarmes, facilitando a tomada de decisão dos operadores de painel [4].

65 As alterações realizadas na automação permitiram, para além de prevenir questões relacionadas com a segurança industrial e ambiental, obter ganhos produtivos, pois foram reduzidas as possibilidades de alarmes mais importantes serem ignorados face ao excessivo número de alarmes que anteriormente eram gerados.

\subsubsection{A perceção de participação}

O Questionário de Avaliação da Participação Percebida (QAPP) foi construído através de revisão da literatura e a partir de entrevistas realizadas a quatro stakeholders. Tendo este instrumento já sido analisado com mais detalhe noutras publicações (Duarte \& Vasconcelos, 2012; Duarte, Vasconcelos \& Monteiro, 2012), iremos aqui unicamente referir que foi respondido por 77 trabalhadores nas sessões de consolidação e disseminação. Uma análise fatorial exploratória permitiu evidenciar três fatores principais presentes nas respostas: "impacto percebido" (relacionado com o modo como os sujeitos percebem o impacto a vários níveis); "perceção de envolvimento" (relacionado com a perceção dos participantes sobre até que ponto foram envolvidos no projeto); e "conflitos associados à participação" (relacionado com os aspetos mais controversos da participação). Ao comparar a média dos valores atribuídos aos itens que compõem cada um destes fatores com o ponto médio da escala, verificou-se que, de um modo significativo, os sujeitos avaliaram positivamente os itens que compõem os fatores "impacto percebido" e "perceção de envolvimento" e negativamente os itens que compõem o fator "conflitos associados à participação". O que mostra que não só consideram que o Projeto teve um impacto positivo e que avaliam positivamente o seu envolvimento, como também desvalorizam a existência de aspetos negativos associados à participação como o medo de represálias ou o facto de apenas a opinião de um dos grupos ser tida em conta.

Como já foi referido anteriormente, para além do QAPP foi pedido aos participantes que enumerassem por escrito, e salvaguardando o seu anonimato, a duas questões abertas (Duarte, Vasconcelos, \& Monteiro, 2012): "Quais sãos os pontos fortes do Projeto Matriosca?" e "O que acha que poderia melhorar no Projeto Matriosca?". 58 participantes responderam a estas questões, tendo-se observado 72 referências a pontos fortes e 28 referências a aspetos a melhorar. Entre os pontos fortes foram referidos aspetos relacionados principalmente com os problemas resolvidos (10 referências ao facto de se terem resolvido problemas e 9 referências ao facto de se terem identificado problemas) e a aspetos metodológicos ( 9 referências ao facto de se terem envolvido os trabalhadores, 7 referências ao facto de se tratar de uma abordagem 
multidisciplinar, 7 referências ao facto de haver um ambiente aberto para a participação e 6 referências ao papel dos psicólogos do trabalho).

No campo dos aspetos a melhorar, as respostas foram mais dispersas; mas destacam-se 5 referências à necessidade da continuidade do processo e 5 referências à necessidade de um maior envolvimento da gestão (o que entra em contradição com 3 referências ao envolvimento da gestão como ponto forte do Projeto Matriosca, o que é em si revelador da complexidade do processo participativo).

\section{A transição para o Matriosca Interno: a permanência do processo}

Perto do final do processo, depois de observados os resultados, os seus atores começaram a mostrar uma preocupação com a permanência da intervenção. Assim, surgiu o Matriosca Interno com o objetivo de adaptar o Projeto Matriosca aos constrangimentos do dia-a-dia.

$70 \mathrm{Na}$ ausência de uma equipa exclusivamente dedicada ao Matriosca Interno, a coordenação passou a ser assegurada por elementos da Direção de Segurança, Higiene e Ambiente - já que acompanharam o Projeto Matriosca desde o início e em todos os seus momentos, trabalhando de uma forma muito próxima com os psicólogos do trabalho. No cenário planeado, manteve-se o princípio do sistema de alternância de sessões de discussão em grupo e momentos de acompanhamento individual em posto de trabalho. Manteve-se também a participação de vários departamentos nos grupos de trabalho e a realização de reuniões de Comité de Acompanhamento entre cada ciclo de formação.

71 Reduziu-se contudo o tempo de discussão em grupo (que de oito horas passou a ser de duas), aproveitando o facto de a maioria dos participantes já estar familiarizada com este modo de trabalhar. Cada elemento ficaria então responsável por identificar uma situação-problema antes de cada sessão e, posteriormente, responsável pelo seu acompanhamento.

Por este facto, tarefas que eram executadas quotidianamente pelos psicólogos do trabalho (nomeadamente: registo sistemático das situações-problema, reuniões de balanço setorial e acompanhamento próximo no terreno da implementação das soluções) deixaram de ser assumidas formalmente.

73 É de salientar ainda que também não houve uma preparação específica dos novos coordenadores para substituírem os psicólogos do trabalho.

74 Foram realizadas quatro sessões do Matriosca Interno em 2012. No entanto, no ano de 2013, uma primeira análise revelou que ainda não tinha sido realizada mais nenhuma sessão.

\section{Discussão}

\subsection{Um processo de transformação bem sucedido}

É manifesto, a partir da análise dos dados apresentados anteriormente, que o Projeto Matriosca desencadeou um processo de transformação ancorado no diagnóstico de 194 situações-problema, possibilitando 87 intervenções (cf. ponto 2.2.1). 

se ter tornado comum para toda a empresa, levou a uma nova consciência da realidade da atividade dos operadores de painel e à discussão multidisciplinar de soluções para a melhoria das suas condições de trabalho, logo da segurança da empresa de um modo geral.

81 Finalmente, a utilização de um questionário (cf. 2.2.1) tornou mais rico e participado o processo de avaliação do Projeto Matriosca. Sendo a participação o catalisador do processo intercomunicante de formação e transformação, é interessante observar que os participantes têm uma perceção positiva acerca do seu envolvimento e do impacto do projeto e uma perceção negativa acerca dos aspetos potencialmente negativos da participação. Apesar de se tratar apenas de opiniões, será um bom indicador a ter em conta - aliás reforçado com as evocações positivas dos participantes quando lhes foram colocadas as questões sobre os pontos fortes e os aspetos a melhorar do projeto.

\subsection{A sustentabilidade do processo: curto prazo/longo prazo}

Se os resultados são muito claros em relação ao potencial transformador deste tipo de participação, respeitadora do trabalho real e da atividade dos diversos atores envolvidos, duas questões ficam em aberto: (i) a quê e a quem (e com que pesos relativos) se deveu esta mudança; (ii) qual a "durabilidade" da mudança no seio da empresa. Estas questões são essenciais para aferir o valor de longo prazo deste modelo de intervenção participativa. Trata de se perceber se, por um lado, a valorização da opinião e dos conhecimentos dos trabalhadores se circunscreveu àquele período temporal; ou se, pelo contrário, se conseguiu introduzir na empresa um novo modo de trabalhar, mais participativo, mais sustentado na realidade das situações de trabalho, logo mais congruente. Consideramos fundamental perceber quais os fatores-chave a assegurar para a continuidade dos processos desencadeados. E neste sentido, convém 
analisar e compreender melhor a dificuldade na implementação do Matriosca Interno, os obstáculos na manutenção de um impacto no longo prazo. Uma questão nos parece aqui central: será a presença dos psicólogos do trabalho no terreno indispensável? Teiger e Laville (1991) concebiam as ações de formação de representantes sindicais com a finalidade de os tornar autónomos em análises e projetos de intervenção posteriores. Será esta finalidade viável em contexto empresarial?

Constatámos, na realidade, que, neste tipo de intervenções, a função do psicólogo do trabalho passa não só por moderar as várias fases do processo em termos logísticos e práticos, mas também por uma atenção constante visando garantir o projeto na sua vertente participativa e sustentada no "real". O seu papel de "guardião da atividade e dos seus interfaces" (Vasconcelos, 2005) abrange, de facto, a sustentação da participação, tornando-a equilibrada e justa, vigiando todas as formas de desequilíbrio e desigualdade: procura garantir que a atividade de todos os envolvidos seja respeitada, mas acompanha igualmente o processo participativo em si, a dinâmica de poderes que lhe subjaz e os compromissos necessários para o processo de tomada de decisões, quer no contexto dos grupos e do Comité de Acompanhamento, quer informalmente. Ora, esta responsabilidade ganha obviamente importância num contexto caraterizado por uma clara desigualdade em termos de relações laborais e hierárquicas, que se reflete no exercício do poder na tomada de decisões.

o que exige esta monitorização de um processo participativo na sua complexidade e relativa fragilidade poderá estar na origem das dificuldades para a transição para um Matriosca Interno, já que tinha sido insuficientemente considerado na sua preparação.

Será, por isso, fundamental aprofundar noutros estudos o que há de específico neste papel que passaremos a designar de "guardião da atividade e do processo participativo". Aliás, está a ser negociada uma análise mais fina do percurso do Matriosca Interno com a empresa referida neste artigo

\section{BIBLIOGRAFIA}

Argyris, C. (1957). Personality and organization. New York: HarperCollins.

Cole, D., Rivilis, I., Van Eerd D., Cullen, K., Irvin, E., \& Kramer, D. (2005). Effectiveness of Participatory Ergonomic Interventions: A Systematic Review. Toronto: Institute for Work \& Health; 2005.

Cole, D. C., Theberge, N., Dixon, S. M., Rivilis, I., Neumann, W.P., \& Wells, R. (2009). Reflecting on a program of participatory ergonomics interventions: a multiple case study. Work, 34, 161-178. doi: 10.3233/WOR-2009-0914

Duarte, S., Pinto, R., \& Vasconcelos, R. (2011). Gestão da formação em segurança numa empresa industrial química: debates entre a rigidez formal e a eficácia potencial a partir de um estudo de caso. In P. Arezes, J. Baptista, M. Barroso, P. Carneiro, P. Cordeiro, N. Costa, R. Melo, A. Miguel, \& G. Perestrelo (Eds.). Occupational Safety and Hygiene - SHO 2011. (pp. 255-260). Guimarães: Sociedade Portuguesa de Segurança e Higiene Ocupacionais. 
Duarte, S., \& Vasconcelos, R. (2012). Assessing the participatory dimension of a hands-on training intervention. In P. Arezes, J. Baptista, M. Barroso, P. Carneiro, P. Cordeiro, N. Costa, R. Melo, A. Miguel \& G. Perestrelo (Eds). Proceedings of SHO 2012 - International Symposium on Occupational Safety and Hygiene. (pp. 231-236) Guimarães: Portuguese Society of Occupational Safety and Hygiene.

Duarte, S., Vasconcelos, R., \& Monteiro, L. (2012). Participation as a tool for the promotion of safer workplaces: a case study of a hand-on training intervention. In P. Mondelo, K. Saarela, W. Karwowski, E. Occhipinti, P. Swuste, \& P. Arezes. (Eds.). Proceedings of the 10th International Occupational Risk Prevention ORP 2012. Bilbao, Spain, 11 p. CD-Rom.

Garrigou, A. (2002). Participatory ergonomics: a risky activity between commitments and reality. French National Report. Brussels: The European Trade Union Technical Bureau for Health and Safety (TUTB).

Gonzalez, M. (2009). The Multidimensional Impact of Workplace Direct Participation in European Jobs. An Assessment of Theory, Debate and Research. In A. Guillén \& S.-Å. Dahl (Eds.). Quality of Work in the European Union: Concept, Data and Debates from a Transnational Perspective. (pp. 187-210). Brussels: P.I.E. Peter Lang.

Haines, H., Wilson, J. R., Vink, P., \& Koningsveld, E. (2002). Validating a framework for participatory ergonomics (the PEF). Ergonomics 45 (4): 309-327.

Imada, A. S. (1991). The rationale and tools of participatory ergonomics. In K. Noro and A. S. Imada (Eds.) Participatory Ergonomics. (pp 30-51). London: Taylor \& Francis.

Lacomblez, M., \& Teiger, C. (2007). Ergonomia, formações e transformações. In P. Falzon (Ed). Ergonomia. (pp.586-602). São Paulo: Edgard Blücher.

Lacomblez, M., \& Vasconcelos, R. (2009). Análise ergonómica da actividade, formação e transformação do trabalho: opções para um desenvolvimento durável. Laboreal, 5, (1), 53-60. http://laboreal.up.pt/revista/artigo.php?id=37t45nSU5471123592231593411

Lamonde, F. (1995). L'ergonomie et la participation des travailleurs. In R. Blouin, R. Boulard, P.A. Lapointe, A. Larocque, J. Mercier, \& S. Montreuil, La réorganisation du travail: Efficacité et Implication, (pp.147-163). Québec: Presses de L’Universtié Laval.

Likert, R. (1961). New patterns of management. New York: McGraw-Hill.

Maciel, R. (1998). Participatory ergonomics and organizational change. International Journal of Industrial Ergonomics, 22, 319-325.

McGregor, D. (1960). The human side of enterprise. New York: McGraw-Hill.

Potterfield, T. (1999). The Business of Employee Empowerment: Democracy and Ideology in the Workplace. Westport, Connecticut: Quorum Books.

Rivilis, I., Van Eerd, D., Cullen, K., Cole, D., Irvin, E., Tyson, J., \&, Mahood, Q. (2008). Effectiveness of participatory ergonomic interventions on health outcomes: a systematic review. Applied Ergonomics, 39 (3), 342-358. doi: 10.1016/j.apergo.2007.08.006

St-Vincent, M., Fernandez, J., Kuorinka, I., Chicoine, D., \& Beaugrand, S. (1997). Assimilation and use of ergonomic knowledge by non-ergonomists to improve jobs in two electrical product assembly plants. Human Factors and Ergonomics in Manufacturing, 7, 337-350.

St-Vincent, M., Vézina, N., Laberge, M., Gonella, M., Lévesque, J., Petitjean-Roget, T., Coulombe, T., Beauvais, A., Ouellet, S., Dubé, J., Lévesque, S., \& Cole, D. (2010). L'intervention ergonomique participative pour prévenir les TMS: ce qu'en dit la littérature francophone. Montréal: IRSST. 
Teiger, C., \& Laville, A. (1991). L'apprentissage de l'analyse ergonomique du travail, outil d'une formation pour l'action. Travail et Emploi, 47, 53-62.

Teiger, C., \& Lacomblez, M. (2013). (Se) Former pour transformer le travail: Dynamiques de constructions d'une analyse critique du travail. Québec: Presses de L'Université Laval.

Vasconcelos, R. (2000). Analisar o trabalho para formar e transformar: A auto-análise do trabalho ao serviço da HST num contexto de desenvolvimento e transmissão de competências. Tese de Mestrado em Psicologia do Trabalho. Porto: FPCEUP.

Vasconcelos, R., \& Lacomblez, M. (2000). Identification and prevention of accident risks through the development of self-analysis-of-work competences among industrial workers. Ergonomics for the new millenium: proceedings of the XIVth triennial congress of the International Ergonomics Association and 44th annual meeting of the human factors and Ergonomics Association, 663-670.

Vasconcelos, R., \& Lacomblez, M. (2002). Análise guiada do trabalho e desenvolvimento de competências profissionais: Contributos, reflexões e desafios. Cadernos de consulta psicológica, 17/18, 295-304.

Vasconcelos, R. (2005) O guardião da actividade e dos seus interfaces: o psicólogo do trabalho na promoção da segurança e saúde no trabalho. Actas do Colóquio Internacional sobre Segurança e Higiene Ocupacionais, Auditório da FEUP, Porto. pp. 87-94, 2005.

Vasconcelos, R. (2008). o papel do psicólogo do trabalho e a tripolaridade dinâmica dos processos de transformação: contributo para a promoção da segurança e saúde no trabalho. Tese de Doutoramento em Psicologia do Trabalho. Porto: FPCEUP.

Vasconcelos, R., Duarte, S., \& Moreira, V. (2010). Matriosca Project: Work Analysis, hands-on training and participative action for accident prevention. In P. Arezes, J. Baptista, M. Barroso, P. Carneiro, P. Cordeiro, N. Costa, R. Melo, A. Miguel, \& G. Perestrelo (Eds.). Occupational Safety and Hygiene - SHO 2010. (pp. 542-546). Guimarães: Portuguese Society of Occupational Safety and Hygiene.

Vasconcelos, R., Silva, D., \& Fortuna, P. (2011). A transformação das condições de trabalho enquanto critério para a avaliação da formação em segurança: reflexões e desafios a partir de um estudo de caso. In P. Arezes, J. Baptista, M. Barroso, P. Carneiro, P. Cordeiro, N. Costa, R. Melo, Miguel, A. \& G. Perestrelo (Eds.). Occupational Safety and Hygiene - SHO 2011. (pp. 622-628). Guimarães: Portuguese Society of Occupational Safety and Hygiene.

Vasconcelos, R., Silva, D., Pinto, R., \& Duarte, S. (2012). Evaluating work and training within an intercommunicating process of change: reflections drawn from a case study on a chemicals industrial company in Portugal. Work: A Journal of Prevention, Assessment and Rehabilitation, 41, 4564-4571. http://iospress.metapress.com/content/E671JN10T2211452.

Wells, D. (1987). Empty promises: Quality of working life programs and the labor movement. New York: Monthly Review Press.

Wilkinson, A., \& Dundon, T. (2010). Direct Employee Participation. In A. Wilkinson, P. Gollan, M. Marchington, \& D. Lewin (Eds.), Oxford Handbook of Participation in Organizations. (pp. 167-185). Oxford: Oxford University Press.

Wilson, J. R., \& Haines, H. M. (1997). Participatory ergonomics. In G.Salvendy (Ed.), Handbook of human factors and ergonomics (pp. 490-513). United States of America: John Wiley and Sons.

Wilson, J. R., Haines, H., \& Morris, W. (2005). Participatory Ergonomics. In J. R. Wilson \& N. Corlett, Evaluation of Human Work (3rd Ed) (pp. 933-962). London: Taylor and Francis. 
Wynne, B. (1988). Unruly Technology: Practical Rules, Impractical Discourses and Public Understanding. Social Studies of Science, 18, 147-167.

Zarifian, P. (1999). Objectif compétence. Paris: Liaisons.

\section{NOTAS}

1. Entendemos que para uma melhor compreensão das categorias em causa seria relevante a apresentação de exemplos de situações-problema. No entanto, devido a compromissos de confidencialidade estabelecidos com a empresa não podemos incluir situações relacionadas com as suas instalações sem a sua autorização que, para este caso, não foi concedida.

2. Abertura de uma página pop-up acompanhado por um sinal luminoso na barra inferior do monitor.

3. Uma fábrica pode parar a sua produção automaticamente sempre que determinado indicador ultrapassa os valores padrão para ele definidos. As quebras de tensão podem contribuir igualmente para a paragem das fábricas, pois ocorrem fortes oscilações na corrente elétrica. Os "momentos de arranque" são, então, períodos do turno em que é necessário iniciar todo o processo produtivo, podendo ter a duração de até 8 horas.

4. Este trabalho de reorganização dos alarmes foi realizado apenas numa fábrica, estando, neste momento, em implementação numa segunda fábrica.

\section{RESUMOS}

Apesar de consensual, a participação é um conceito ambíguo. A análise da atividade é uma forma de garantir que as intervenções participativas sejam mais justas e sustentadas no real. o Projeto Matriosca é um exemplo de uma intervenção participativa em que o recurso à análise da atividade por parte dos consultores que a conduzem é essencial. Esta intervenção, focada no incremento da segurança e saúde no trabalho, foi implementada numa empresa do setor químico e teve impacto visível e reconhecido pelos participantes. Apesar de ter havido no seio da empresa uma intenção de conti-nuar o processo com recursos internos e de ter sido definido um procedimento para tal, não é claro que se tenham conseguido alcançar o objetivo. A discussão deste caso desemboca numa reflexão acerca da importância da análise da atividade e do recurso a profissionais que a dominem, bem como de outras condições metodológicas, contextuais e estratégicas a considerar na conceção e análise deste tipo de intervenções.

Aunque la participación es un concepto consensual, todavía permanece ambiguo. Una manera de hacer las intervenciones participativas más justas y basadas en la realidad es utilizando el análisis de la actividad. El Proyecto Matriosca es un ejemplo de una intervención participativa en la cual la utilización del análisis de la actividad por los consultores que condujeran la intervención, fue esencial. Esta intervención, enfocada en el incremento de la seguridad y salud en el trabajo, fue implementada en una empresa del sector químico y ha tenido un impacto visible y reconocido por los participantes. A pesar de la intención de seguir con el proceso internamente y de, incluso, haber sido definido un procedimiento organizacional para ello, no queda claro que ese objetivo se haya logrado. La discusión de este caso culmina con una reflexión sobre la importancia del 
análisis de la actividad y del recurso a profesionales que la dominen, además de otras condiciones metodológicas, contextuales y estratégicas que deberían ser consideradas en la concepción y análisis de este tipo de intervenciones.

Bien que consensuelle, la participation est un concept ambi-gu. Une façon de rendre les interventions participatives plus justes et durables est de recourir à l'analyse de l'activité. Le Projet "Matriosca" est l'un des exemples d'une intervention participative où le recours à l'analyse de l'activité de la part des consultants qui la conduisent est essentiel. Cette intervention, dont la finalité s'inscrit dans une promotion de la sécurité et de la santé au travail, a été développée dans une entreprise du secteur chimique et a eu un impact visible et reconnu par les participants. Malgré l'intention de poursuivre ce projet au sein de l'entreprise, mais sans recours aux consultants, et bien qu'un processus ait été défini dans ce sens, il n'est pas évident que cette seconde phase ait été une réussite. La discussion de ce cas soutient une réflexion relative à l'importance de l'analyse de l'activité et du recours à des professionnels qui la dominent, ainsi qu'à d'autres conditions méthodologiques, contextuelles et stratégiques à considérer dans la conception de ce type d'intervention.

Despite its consensual nature, participation is an ambiguous concept. Resorting to activity analysis is one way to make participatory interventions fairer and more sustainable. The Matriosca Project is an example of a participatory interven-tion in which the use of activity analysis by the consultants is an essential part. This intervention, focused on increasing safety and health at work, was implemented in a chemical company and had an impact that was visible and recognized by the participants. The company's intention was to continue the process internally and a procedure was set out with that purpose, but it is not clear that this goal was achieved. The discussion of this case culminates in a reflection on the impor-tance of activity analysis and the collaboration of profession-als that master it, as well as of other methodological, contex-tual and strategic conditions to consider when designing and analyzing this type of interventions.

\section{ÍNDICE}

Mots-clés: analyse de l'activité, participation, Matriosca, formation-ac-tion, durabilité Palavras-chave: análise da atividade, participação, Matriosca, formação-ação, sustentabilidade Keywords: activity analysis, participation, Matriosca, action-training, sustainability Palabras claves: análisis de la actividad, participación, Matriosca, aprendizaje en la acción, sostenibilidad

\section{AUTORES}

\section{SÉRGIO DUARTE}

Centro de Psicologia da Universidade do Porto. Faculdade de Psicologia e de Ciências da Educação da Universidade do Porto. Rua Alfredo Allen 4200-135 Porto, Portugal pdpsi10005@fpce.up.pt

\section{RICARDO VASCONCELOS}

Mota-Engil México SA de CV, Horacio \#828, Col. Polanco, IV Sección, Del. Miguel Hidalgo, México DF, C.P. 11550, México

Ricardo.Vasconcelos@mota-engil.com.mx 